\title{
Correlation between the internal length, the fracture process zone and size effect in model materials
}

\author{
K. Haidar ${ }^{1}$, G. Pijaudier-Cabot ${ }^{1}$, J.F. Dubé ${ }^{2}$ and A. Loukili ${ }^{1}$ \\ (1) R\&DO - Institut de Recherche en Génie Civil et Mécanique (GeM), UMR CNRS 6183, Ecole Centrale de Nantes, France \\ (2) LMGC, UMR5508, Université Montpellier, France.
}

\begin{abstract}
In this paper, we examine the correlation between the width of the fracture process zone, the parameters entering in the description of size effect (related to the dimension of the specimen especially), and the internal length in non local constitutive relations for a model mortar material with a controlled macro-porosity. Experimental investigations on this material in compression, bending, acoustic emission measurements and their analysis are detailed. The experiments show a good agreement between the evolution of Bažant's size effect parameter $d_{0}$ and the evolution of the width of the FPZ. The internal length obtained with the help of inverse finite element analysis is also proportional to these quantities. This correlation provides a reasonable approximation of the internal length, from an experimental test on specimens of a single size directly, equipped with acoustic emission localization devices.

\section{RÉSUMÉ}

Dans cet article, nous examinons les corrélations entre la largeur de la zone de microfissuration (FPZ), les paramètres entrant dans la description de l'effet d'échelle et la longueur interne du modèle d'endommagement non local pour un mortier à macro-porosité contrôlée. Des résultats expérimentaux sur ce matériau en compression, en flexion ainsi que des mesures d'émission acoustiques et leur analyse sont présentés. Les résultats d'essais montrent une bonne corrélation entre l'évolution du paramètre do paramètre de la loi d'effet d'échelle de Bažant, et la largeur de la FPZ. La longueur interne obtenue numériquement par analyse inverse est aussi proportionnelle à ces paramètres. Une bonne approximation de la longueur interne à partir d'essais sur une seule taille d'éprouvette équipée d'un système d'émission acoustique est aussi obtemue.
\end{abstract}

\section{INTRODUCTION}

In quasi-brittle materials, fracture exhibits a finite size fracture process zone (FPZ). Macro-cracking is the result of progressive material damage in which micro-cracks appear first in a rather diffuse way, and then coalescence occurs in order to form the macro-crack. The size of the resulting fracture process zone is not dependent on the structural size, provided it does not interfere with the boundaries of the considered body. It is controlled by local heterogeneities, and by the state of stress as well. A consequence of the existence of such a FPZ is structural size effect [1]. Since the ratio of the volume of the FPZ to the total volume of the structure changes for geometrically similar specimens, a size effect on the structural strength is observed experimentally. It is milder than the structural size effect observed in linear elastic fracture mechanics (LEFM) but often more pronounced than the statistical size effect, e.g. described by Weibull's theory. In fact, it is a transitional size effect between strength of material theories and LEFM. From the modeling point of view, the description of the FPZ has to involve the introduction of an internal length in the governing constitutive equations. It can be in the form of a characteristic length which is related to the length of the process zone, Irwin's length or the size of the cohesive zone in Hillerborg's model [2], or in the form of an internal length in non local constitutive relations as defined among many others [3]. This internal length can be related to the width of the fracture process zone [4-6]. Those constitutive theories do predict size effect on the structural strength. In fact a proper description of the response of geometrically similar 
specimens can serve as a good method of calibration of the model parameters, including the internal length of the material $[7,8]$.

One of the open issues in non local modeling is direct measurement of this internal length or, in other words, experimental techniques which aim at observing the fracture process zone. Measurements of displacement fields $[9,10]$ is a possibility but still it is an indirect one since cracking is deduced from large strain gradients. In some polymers for instance, cracking can be directly observed with optical techniques that can hardly be devised if the specimen is not translucid. X-ray techniques have also been considered with success [11]. For cementitious materials, this method is quite demanding in term of energy of X-rays if one wants to achieve the resolution that is required in order to detect small microcracks (with an opening that is of the order of microns). Other research efforts have been reported to estimate the extent of the FPZ in concrete using the ultrasonic pulse velocity technique $[12,13]$. Acoustic emission (AE) is also an experimental tool well suited for monitoring fracture processes. The elastic wave generated by cracking events can be measured and processed using seismic analysis techniques. The strength of $\mathrm{AE}$ techniques is the ability to monitor microscopic damage occurring inside the material. Several works have focused on relating acoustic emission characteristics to the properties of the fracture process zone [14], and $\mathrm{AE}$ source localization analysis to the damage distribution [15]. Mihashi et al. [16] applied three-dimensional acoustic emission techniques to study the FPZ. The results revealed that micro-cracking occurs randomly around the macro-crack and that the FPZ expands after peak load due to the presence of aggregates. Otsuka et al. [17] show that the location of cracks, obtained by the $\mathrm{AE}$ method, has a close relation to the extent of the fracture process zones observed with X-rays.

The aim of this contribution is to examine the experimental correlation between the width of the fracture process zone observed with $\mathrm{AE}$ analysis, the parameters entering in the description of size effect, and the internal length in non local constitutive relations. In order to examine such a correlation, an experimental program on mortar and model materials with controlled (macro) porosity is presented in the next section. Results are discussed in section 3. The correlations between size effect parameters, the width of the FPZ and the internal length of the material obtained from inverse analysis of size effect tests are discussed in section 4 .

\section{EXPERIMENTS ON MORTAR AND MODEL MATERIALS}

The experimental program has been designed in order to measure the mechanical characteristics of mortar specimens with a controlled microstructure [18]. This control was achieved by adding inclusions of weak mechanical characteristics (polystyrene beads) in a mortar matrix. Depending on the amount of inclusions added in the cementitious matrix, variations of the elastic properties, of the tensile and compressive strengths and of the fracture energy are expected. Data on this simple model material are also expected to be correlated with homogenization theories.

All test specimens were made with a mix which consists of ordinary Portland cement CPA-CEMI 52.5, polystyrene beads, normal density fine sand with a maximum size of $2 \mathrm{~mm}$, a superplasticizing agent (Glenium 51) and water. Expanded polystyrene spheres of 3-7 mm mean diameter were used as aggregate in the mix design. The spheres have a mass density of $20 \mathrm{~kg} / \mathrm{m} 3$, a Young's modulus of $7 \mathrm{MPa}$ and a compressive strength of $80 \mathrm{kPa}$. Expanded polystyrene consists essentially of air $98 \%$. It is hydrophobic [19]. Mix preparation is particularly important when using such very lightweight aggregates. Expanded polystyrene tends to float on the top of the moulds during vibration, increasing the risk of poor mix distribution and segregation. Based on Yamura and Yamuchi [20] and Perry et al. [21], controlled mix conditions were achieved by mixing the dry sand and cement before adding the water and then the superplasticizer. After sufficient mixing time ( $2-3$ minutes), the polystyrene beads were added and thoroughly mixed into the mortar. In order to minimize segregation, vibration was avoided, and all test specimens were compacted by hand tamping. Fig. 1 shows the distribution of polystyrene beads achieved for the mix with the lowest density (1.4).

Four different mixes of densities 2.0, 1.8, 1.6 and 1.4, having polystyrene content $\mathrm{g}$ of $13,22,31$ and $39 \%$ respectively, were achieved for the present test program (Table 1), in addition to the reference material (mortar without inclusions). All mixes have a cement/sand ratio of 0.46 and a water/cement ratio of 0.4 . The polystyrene content $\mathrm{g} \%$ (in volume) which must be incorporated to obtain the desired density is calculated from the formula:

$$
g=\frac{d_{m}-d_{b}}{d_{m}-d_{p}}
$$

where $d_{b}$ is the density of the desired mixture, $d_{m}$ is the density of the reference mortar, and $d_{p}$ is the density of the polystyrene beads.

Cylindrical concrete specimens of diameter $11 \mathrm{~cm}$ and

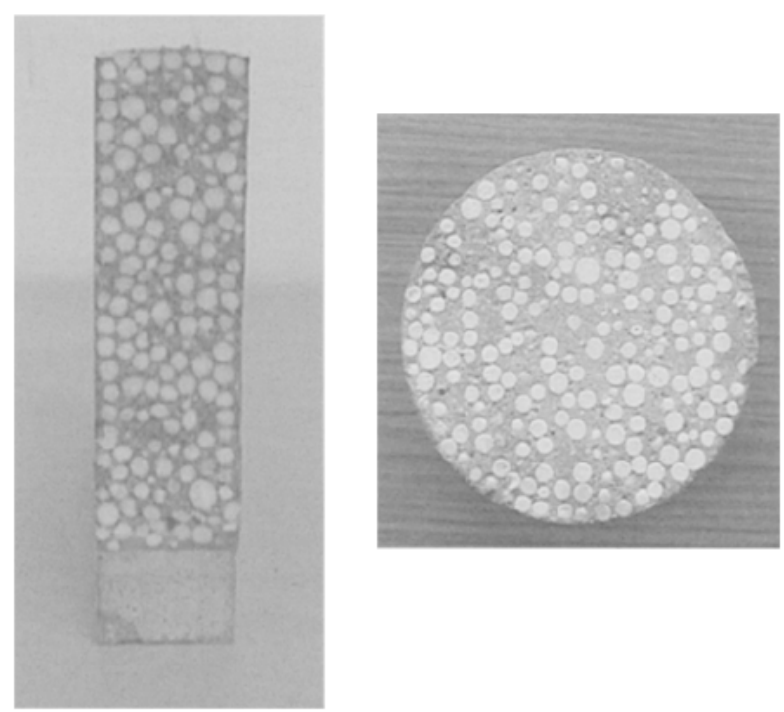

Fig. 1 - Distribution of polystyrene beads in 1.4 density mixture. 


\begin{tabular}{|c|c|c|c|c|c|}
\hline \multicolumn{7}{|c|}{ Table 1 - Mortar mixture proportions } \\
\hline Mix & ECH0 & ECH1 & ECH2 & ECH3 & ECH4 \\
\hline Density & 2.3 & 2.0 & 1.8 & 1.6 & 1.4 \\
\hline Cement $\left(\mathrm{kg} / \mathrm{m}^{3}\right)$ & 640 & 558 & 502 & 446 & 389 \\
\hline Sand $\left(\mathrm{kg} / \mathrm{m}^{3}\right)$ & 1395 & 1215 & 1096 & 969 & 846 \\
\hline polystyrene $\left(\mathrm{kg} / \mathrm{m}^{3}\right)$ & 0.0 & 2.16 & 4.31 & 5.16 & 6.65 \\
\hline Superplastizer $\left(\mathrm{kg} / \mathrm{m}^{3}\right)$ & 6.4 & 5.58 & 5.02 & 4.46 & 3.89 \\
\hline Water $\left(1 / \mathrm{m}^{3}\right)$ & 250 & 219 & 197 & 175 & 153 \\
\hline Slump $(\mathrm{cm})$ & 12.2 & 9.45 & 7.5 & 5.15 & 2.15 \\
\hline
\end{tabular}

\begin{tabular}{|c|c|c|c|c|c|}
\hline \multicolumn{5}{|c|}{ Table 2 - Mechanical properties of test mix } \\
\hline Mix & ECH0 & ECH1 & ECH2 & ECH3 & ECH4 \\
\hline $\mathrm{f}_{\mathrm{c}}(\mathrm{MPa})$ & 59.8 & 36.8 & 27.6 & 23.7 & 16.1 \\
\hline $\mathrm{f}_{\mathrm{t}}(\mathrm{MPa})$ & 4.27 & 3.93 & 3.05 & 2.35 & 1.82 \\
\hline $\mathrm{E}_{\mathrm{c}}(\mathrm{GPa})$ & 33.4 & 25.9 & 23 & 17.2 & 14 \\
\hline
\end{tabular}

values, measured at one third of the failure stress of $25900-23000-17200$ and $14000 \mathrm{MPa}$ respectively. Compared to the Young's modulus of the reference material ECH0, the decrease is $22-31-49$ and $58 \%$ respectively. Concerning the compressive strength, the decrease is about $40,54,61$ and $72 \%$ compared to the compressive strength of the reference material.

length $22 \mathrm{~cm}$ were used for compressive tests. For the bending tests, four different sizes of geometrically notched concrete specimens were used. The depths were $\mathrm{D}=40,80,160$ and $320 \mathrm{~mm}$ while the thickness was kept constant for all the specimens $b=40 \mathrm{~mm}$. The length to depth ratio was $L / D=8: 3$ and the span to depth ratio was $1 / D=2.5$ for all specimens. One notch of depth $\mathrm{D} / 6$ and thickness $1.5 \mathrm{~mm}$ (same for all dimensions) was placed in each bending specimen by putting steel plates in the moulds before casting (Fig. 2). For the acoustic emission measurements, only specimens of depth $\mathrm{D}=$ $160 \mathrm{~mm}$ were tested. Three identical specimens were cast simultaneously from each successive batch, for each type of test. Curing conditions were 28 days at $100 \% \mathrm{RH}$ and $20^{\circ} \mathrm{C}$.

\subsection{Elastic properties and compressive strength}

The compression tests were performed using $300 \mathrm{kN}$ capacity hydraulic testing machine at a loading rate of $0.5 \mathrm{MPa} / \mathrm{s}$ until failure. The compressive strength $f_{c}$, tensile strength $f_{t}$ and the Young's modulus $E_{c}$ change significantly with the polystyrene content (Table 2). Mixtures ECH1 ECH2 - ECH3 and ECH4 showed nominal elastic modulus

(a)

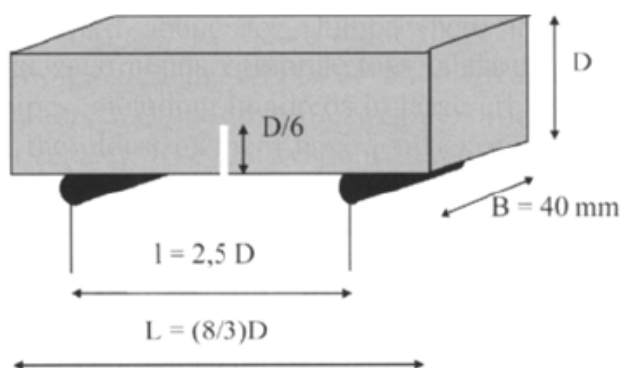

(b)

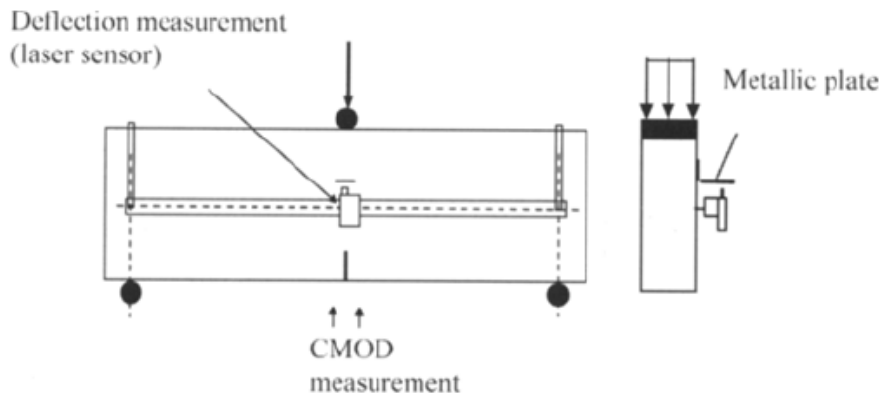

Fig. 2 - (a) Description of mortar samples; (b) Description of instrumentation for the bending tests.
For the Young's modulus at least, these data can be compared with results from homogenization theories. A possible candidate, among many others, is the well known formula $[22,23]$

$$
\frac{E_{c}}{E_{0}}=(1-g)^{2}
$$

where $E_{c}$ is the Young's modulus of the material with polystyrene content $g$ and $E_{0}$ is the Young's modulus of the reference material. Fig. 3 compares the measured values of elastic modulus with the above equation. A very good agreement is obtained.

\subsection{Size effect tests}

The size effect tests followed the guidelines established by RILEM [24] using a closed - loop testing machine, (a $160 \mathrm{kN}$ capacity INSTRON machine). The tests were notch opening controlled with a constant CMOD rate of $0.1 \mu \mathrm{m} / \mathrm{s}$ for $D=40$ $80 \mathrm{~mm} ; 0.20 \mu \mathrm{m} / \mathrm{s}$ for $D=160 \mathrm{~mm}$ and $0.25 \mu \mathrm{m} / \mathrm{s}$ for $D=$ $320 \mathrm{~mm}$. For each size and each mix, the dispersion over the three specimens tested is quite small and in the following we are going to show average curves only. Fig. 4 shows the response of medium size specimen $(D=40 \mathrm{~mm})$ for each material density. Note that the deflection at peak is almost independent from the density of the material. The material density influences still the mechanical behavior of beams; the lower the density, the lower the stiffness and the peak load. Fig. 5 shows the average load - deflection plots for the four sizes of beam and for the five different densities.

These data are going to be interpreted with the help of Bažant's size effect law. This theory is here restricted to the dependence of the nominal stress at failure $\sigma_{\mathrm{N}}$ on the characteristic dimension $D$ of $2 \mathrm{D}$ geometrically similar specimens. For stress - based failure theories such as the plastic limit analysis or elastic allowable strength design, there is no size effect, $\sigma_{\mathrm{N}}$ is constant. For classical linear elastic fracture mechanics, $\sigma_{\mathrm{N}} \alpha D^{-1 / 2}$. Due to the influence of a relatively large micro-cracked zone that blunts the crack front in concrete, size effect is intermediate between strength of materials and linear fracture 


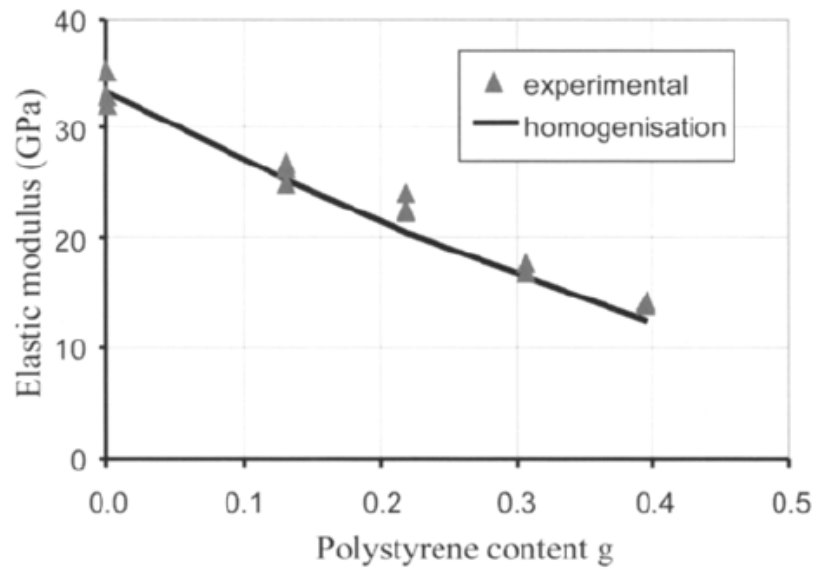

Fig. 3 - Variation of elastic modulus with polystyrene content.

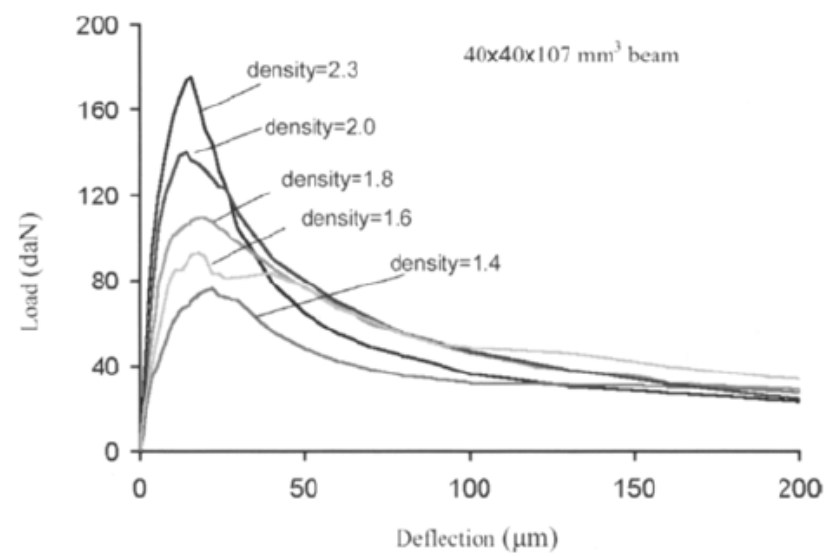

Fig. 4 - Influence of density on structural behavior, average loaddeflection curves for different material density on $40 \times 40 \times 107 \mathrm{~mm}^{3}$ beams.

mechanics and it represents a transition from the former to the latter design criteria as the size increased. This transition is described by the approximate formula:

$$
\sigma_{N}=\frac{B f_{t}}{\sqrt{1+\beta}} \text { with } \beta=D / d_{0}
$$

where $f_{t}$ is the tensile strength of the material, $d_{0}$ is a characteristic size that corresponds to a change of mechanisms between plasticity phenomena and fracture mechanics, and $B$ is a material parameter which is a function of the geometry of the specimen and applied load. $\sigma_{N}$ is calculated according to the classical formula for a beam of unit thickness:

$$
\sigma_{N}=\frac{3}{2} \frac{F L}{0.83 D^{2}}
$$

where $F$ is the maximal load and $L$ is the length between supports. The peak forces are obtained from load - deflection curves in Fig. 5, for each size and for each density. The nominal strengths (calculated from Equation (4)) are given in Table 3 .

The values of $B f_{t}$ and $d_{0}$ in Equation (3) are obtained from a linear regression:
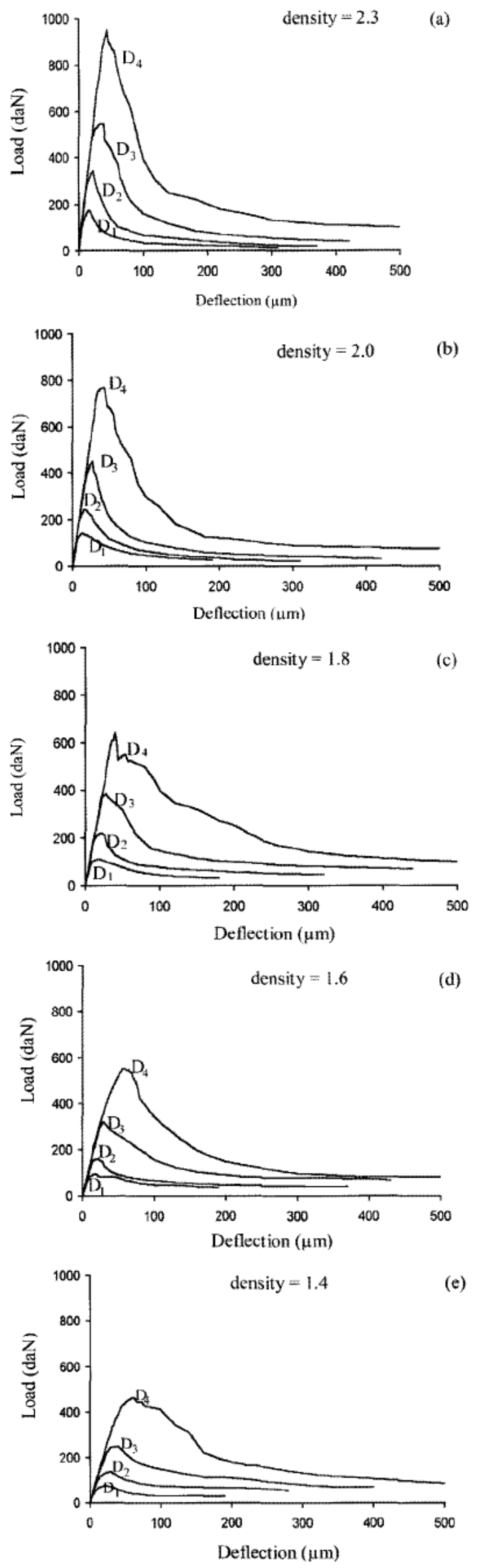

Fig. 5 - Curves representing for each size the average loaddeflection responses for each material density tested. 


\begin{tabular}{|c|c|c|c|c|c|c|}
\hline \multicolumn{7}{|c|}{$\begin{array}{l}\text { Table } 3 \text { - Maximum strength and fracture parameters } \\
\text { obtained from size effect analysis for each density }\end{array}$} \\
\hline \multirow{2}{*}{ MIX } & \multicolumn{4}{|c|}{$\sigma(\mathrm{MPa})$} & \multirow{2}{*}{$\begin{array}{c}\mathrm{d}_{0} \\
(\mathrm{~mm})\end{array}$} & \multirow{2}{*}{$\begin{array}{c}\mathrm{G}_{\mathrm{f}} \\
(\mathrm{N} / \mathrm{m})\end{array}$} \\
\hline & $\mathrm{D} 1=40 \mathrm{~mm}$ & $\mathrm{D} 2=80 \mathrm{~mm}$ & $\mathrm{D} 3=160 \mathrm{~mm}$ & $\mathrm{D} 4=320 \mathrm{~mm}$ & & \\
\hline $\mathrm{ECH} 0$ & 3.99 & 3.64 & 3.21 & 2.82 & 258 & 88.50 \\
\hline $\mathrm{ECH} 1$ & 3.26 & 2.82 & 2.39 & 2.32 & 318 & 72.40 \\
\hline $\mathrm{ECH} 2$ & 2.51 & 2.18 & 2.21 & 1.9 & 435 & 66.50 \\
\hline ECH3 & 2.22 & 1.86 & 1.92 & 1.65 & 463 & 59.70 \\
\hline ECH4 & 1.76 & 1.61 & 1.48 & 1.39 & 484 & 52.30 \\
\hline
\end{tabular}

the background noise, the signal detection threshold was set at a value of about $30 \mathrm{~dB}$ (value adjusted before every test).

The accuracy of the localization of acoustic events was tested before applying any load. An event was generated at several locations on the surface of the specimens, where the transducers were placed, and the results from the localization software were compared with the true location of this event. The accuracy of the technique ranged from $\pm 4 \mathrm{~mm}$ for the reference mortar to $\pm 10 \mathrm{~mm}$ for the lighter material tested

$Y=A X+C$

in which

$X=D, Y=\left(\frac{1}{\sigma_{N}}\right)^{2}, B f_{t}=\frac{1}{\sqrt{C}}, d_{0}=\frac{C}{A}$

The fracture energy $G_{f}$, defined as the energy release rate required for crack growth in an infinitely large specimen, is calculated from the formula:

$$
G_{f}=\frac{g\left(\alpha_{0}\right)}{E_{c} \cdot A}
$$

where $\alpha_{0}=a_{0} / D, a_{0}$ is the notch length, $D$ is the beam depth, and $g\left(\alpha_{0}\right)$ is a non-dimensional energy release rate of the specimen according to the linear elastic fracture mechanics, which can be found for basic specimen geometries in handbooks [25].

From the data in Table 3, it is found that the fracture energy $G_{f}$ shifts from the value $88.5 \mathrm{~N} / \mathrm{m}$ for the reference material to $52.30 \mathrm{~N} / \mathrm{m}$ for the material density 1.4 , a decrease of $41 \%$ (Table 3). In Fig. 6, results are presented in a $\log \left(\sigma / B f_{t}\right)$ v.s. $\log \left(D / d_{0}\right)$ diagram only for the two extreme densities 1.4 and 2.3 for more clarity. The strength of material criterion and the LEFM criterion are also shown. The larger the beam, the lower the relative strength. It can be noticed that the failure of the beams with polystyrene (density $=1.4$ ) tends to adhere more to strength of material than to fracture mechanics, since the corresponding data shift right on the size effect plot. It means that the material becomes more ductile as the density decreases (increasing porosity).

\section{ACCOUSTIC EMISSION ANALYSIS}

The AE system comprised of an eight-channel MISTRAS system, a general-purpose interface bus (PCI-DISP4) and a PC for data storage analysis. Three piezoelectric transducers (resonant frequency of $150 \mathrm{kHz}$ ) were used. Transducers were placed around the expected location of the process zone to minimize errors in the $\mathrm{AE}$ event localization program. They were placed on one side of the specimen, in a triangular array (Fig. 7) and coupled to the specimen with silicon. The detected signals were amplified with a $40 \mathrm{~dB}$ gain differential amplifier in a frequency band from 20 to $1200 \mathrm{kHz}$. In order to overcome (density 1.8). Similar simulations where performed on the opposite side of the location of the transducers, using an HSU Nielsen simulator. The aim is to know the effect of the beam thickness on the localization of AE events. Again an acceptable accuracy was observed with values ranging from $\pm 5 \mathrm{~mm}$ for the reference mortar to $\pm 8 \mathrm{~mm}$ for the lighter material tested. Overall the incertitude of $\mathrm{AE}$ measurements is in the range of the inclusion size. The decrease of accuracy as the amount of inclusions increases in the material can be explained by dispersion effects which become more and more pronounced as the number of particles increases and their relative distance decreases. $\mathrm{AE}$ analysis was performed on specimens of size $\left(40 \times 160 \times 428 \mathrm{~mm}^{3}\right)$ and for three different material densities $(2.3,2.0$ and 1.8$)$ with which localization errors

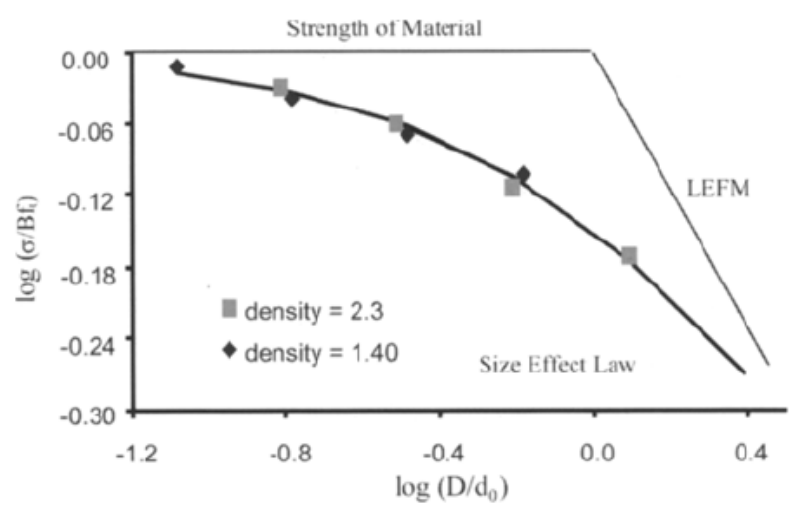

Fig. 6 - Bažant's size effect law for material densities of 2.3 and 1.4.

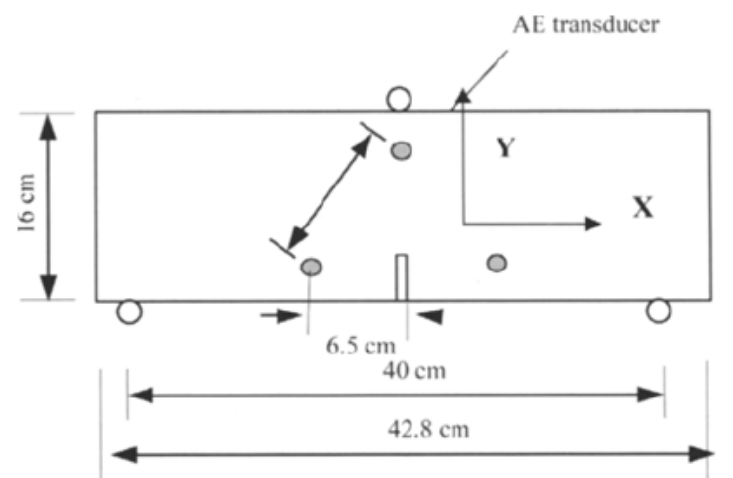

Fig. 7 - Specimen geometry and AE transducers placement. 

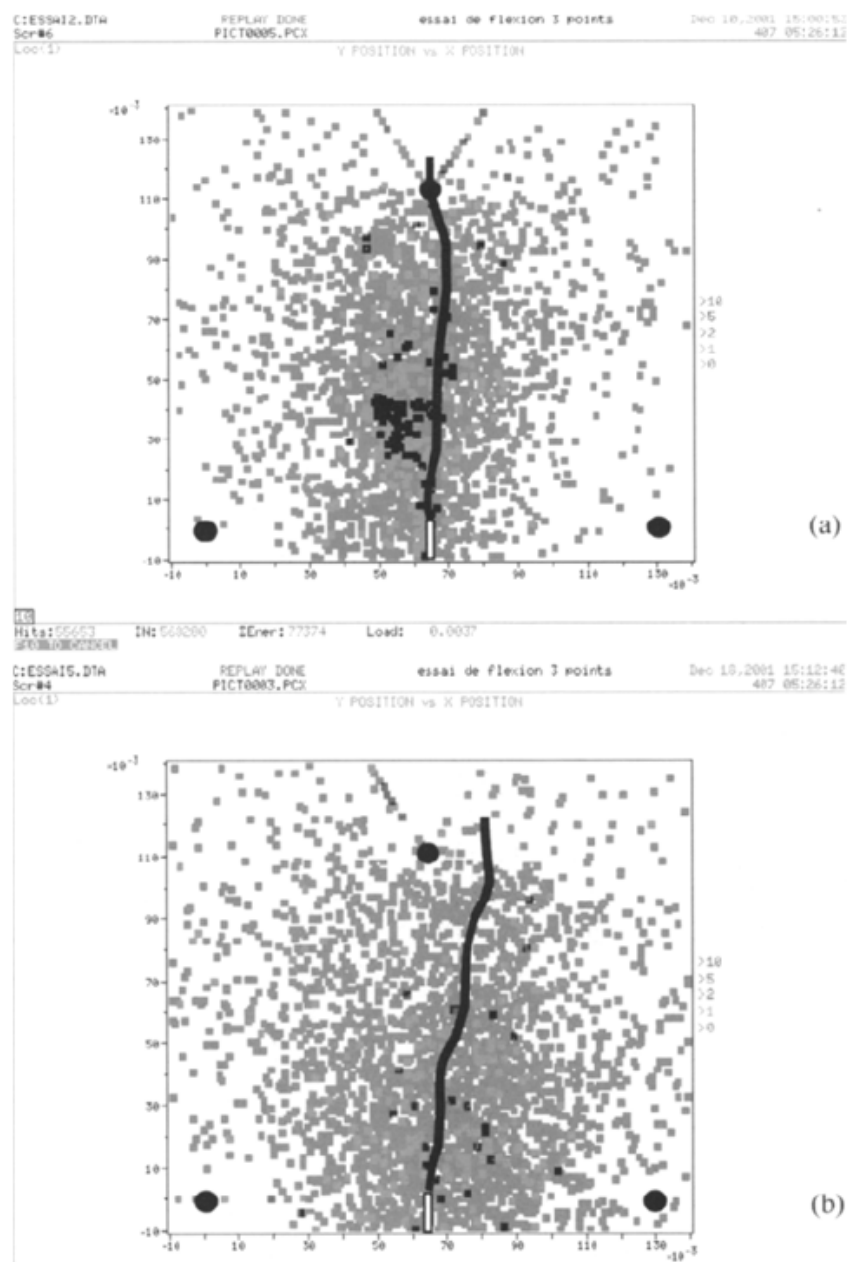

(b)

\section{田}

Fig. 8 - Cumulative location of AE events: (a) material density 2.3; (b) material density 1.8 .

are less or equal to $\pm 10 \mathrm{~mm}$.

The cumulated locations of acoustic events throughout a test are shown in Fig. 8: the plotted points indicate the detected $\mathrm{AE}$ sources over a window of observation centered at the notch of width $130 \mathrm{~mm}$ and covering the beam depth. For the specimen with density $2.3, \mathrm{AE}$ events are located into a smaller region than for the specimen with the lower density. In the same figure, we have plotted the observed crack path that appeared after the test on the lateral surface of the specimen.

The major aim of the $\mathrm{AE}$ analysis is to obtain an experimental characterization of the FPZ. More specifically, it is the width of the FPZ which is the quantity of interest since it is related to the internal length in continuum models [4] and to the parameter $d_{0}$ obtained from Bažant's size effect analysis [4]. A useful approach, well suited to measure the crack band width, is to divide the specimen into an array of rectangular elements and to count the $\mathrm{AE}$ events located within each element. The fineness of the grid should give a sufficient number of events per element and it should not be too small compared to the accuracy of the AE localization method. A grid of size $1 \times 1 \mathrm{~cm}$ is used here. The cumulative number of events, i.e. the sum over the entire record during the experiment, is plotted as a function of its horizontal position $\mathrm{x}$ for various vertical positions y over the depth of the specimen, (a)

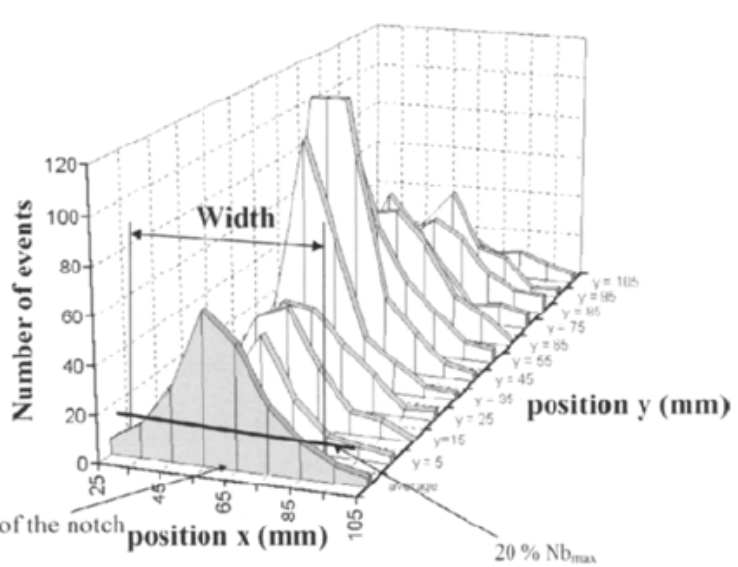

(b)

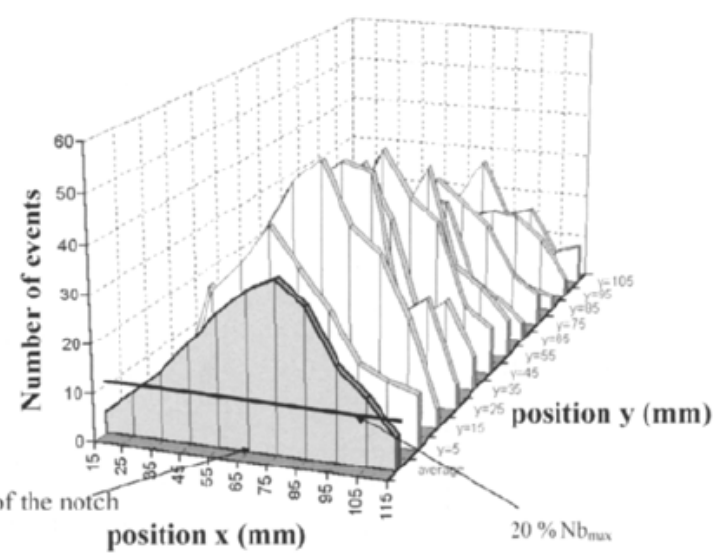

Fig. 9 - Evolution of cumulative events per grid: (a) material density 2.3 ; (b) material density 1.8 .

and for densities 2.3 and 1.8 (Fig. 9). $\mathrm{x}=65 \mathrm{~mm}$ corresponds to the location of the notch. The average curve in both cases is also presented in grey color.

We have plotted in the same graph the horizontal straight line which intersects the vertical axis at the value $=20 \%$ of Nbmax (Nbmax is the maximum number of events on the average curve). Then, we define the crack band width arbitrarily as the length of the segment of this horizontal straight line which intersects the average distribution of $\mathrm{AE}$ events (Fig. 9). This value is about 50, 67 and $85 \mathrm{~mm}$ for the material density $2.3,2.0$ and 1.8 respectively. Fig. 10 shows the evolution of the width of the FPZ defined according to this criterion with the mass density of the specimens. We have also studied the case where the horizontal straight line intersects the vertical axis at the value $=10 \%$ of Nbmax, and we have observed that the evolution of the width of the FPZ, as a function of the polystyrene content $\mathrm{g}$, is the same as shown in Fig. 10. On the same graph, the evolution of $d_{0}$, of the fracture energy Gf of the tensile strength $\mathrm{ft}$ and of the Young's modulus E are also plotted. Note that there is a very good agreement between the evolution of $d_{0}$ and the evolution of the width of the FPZ. For the reference material $d_{0}=258 \mathrm{~mm}$ and the width of the FPZ is $50 \mathrm{~mm}$. The ratio $d_{0} / \mathrm{FPZ}=5.16$ depends of course on the cut off criterion employed in order to define the width of the FPZ in Fig. 9, $10 \%$ or $20 \%$ of Nbmax. 


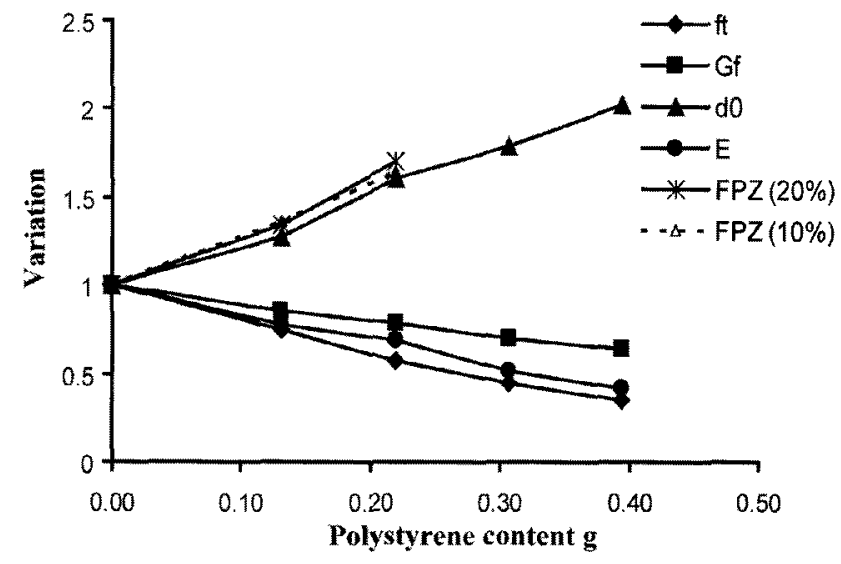

Fig. 10 - Evolution of mechanical properties with polystyrene content.

\section{CORRELATION WITH THE INTERNAL LENGTH}

We are going now to compare the experimental quantities determined in the previous section, namely the width of the FPZ and the parameter $d_{0}$, with the internal length in a continuum model. This internal length is obtained with the help of inverse finite element analysis, following the procedure described by Le Bellégo et al. [8]. Let us first recall briefly the constitutive equations that will be implemented in the computations.

Non local damage model and calibration from size effect experiments

The non local version of the isotropic damage model due to Mazars [27] has been used for the present study. Note that any other model could have been used equivalently, provided it contains an internal length. The results would differ only by the ratio of the width of the FPZ to the internal length. In the reversible (elastic) domain, the stressstrain relation reads:

$$
\sigma=(1-d) D e: \varepsilon
$$

where $\varepsilon$ is the strain tensor, and $D_{e}$ is the elastic stiffness of the material in the absence of damage. $d$ is the damage scalar variable which varies between 0 and 1 . In the non local version of this model, the growth of damage is controlled by the average $\bar{\varepsilon}$ of an equivalent strain $\xi$ defined as:

$$
\xi=\sqrt{\sum_{i=1}^{3}\left(\left\langle\varepsilon_{i}\right\rangle_{+}\right)^{2}}
$$

where $\varepsilon_{i}$ are the principal strains and \langle\rangle$_{+}$is the Macauley bracket. The average (non local) equivalent strain is

$\bar{\varepsilon}(x)=\frac{1}{V_{r}(x)} \int_{\Omega} \psi(x-s) \xi(s) d s$ with $V_{r}(x)=\int_{\Omega} \psi(x-s) d s$ where $\Omega$ is the volume of the structure, $\operatorname{Vr}(x)$ is the representative volume at point $\mathrm{x}$, and $\psi(x-s)$ is the weight function:

$$
\psi(x-s)=\exp \left(\frac{4\|x-s\|^{2}}{l_{c}^{2}}\right)
$$

$l_{c}$ is the internal length of the non local continuum. The loading function is $f(\bar{\varepsilon}, \kappa)=\bar{\varepsilon}-\kappa$, where $\kappa$ is the hardening softening variable. The contour $f(\bar{\varepsilon}, \kappa)=0$ defines the domain of reversible behaviour and the growth of damage is defined with classical Kuhn-Tucker conditions. The damage evolution laws are as proposed by Mazars (1984). In particular, the tensile damage growth is:

$d_{t}=1-\frac{\kappa o(1-A t)}{\kappa} \frac{A t}{\exp \left(B_{t}(\kappa-\kappa 0)\right)}$

Constants At, Bt are model parameters. The calibration procedure aims at obtaining the model parameters that are involved in the tensile response of concrete only. It is based on a simultaneous fit of the numerical and experimental load deflection curves for the four sizes of specimens. The procedure uses a Levengerg-Marquardt algorithm [8]. Fig. 11 shows the fits obtained for the reference material and for the lowest material density (1.4). The internal lengths and the others model parameters obtained as a result of these fits are reported in Table 4. The internal length increases by $43 \%$ and the damage threshold is approximately unchanged for the material density 1.4 , compared to that of the reference material.

\section{CORRELATION WITH EXPERIMENTAL DATA}

The distribution of damage for specimen $\left(40 \times 160 \times 428 \mathrm{~mm}^{3}\right)$, obtained with the finite element computation at the final load step is presented in Fig. 12a. Same as for the acoustic emission tests we have plotted the damage profiles, over the same window of observation as for the $\mathrm{AE}$ analysis, at the final load step, and as a function of its horizontal position $\mathrm{x}$ for various vertical position $\mathrm{y}$ over the specimen (Fig. 12b). The average curve is presented in grey colour. We define the width of the numerical FPZ following the same technique as for $\mathrm{AE}$ analyses. $\mathrm{Nb}_{\max }$ is replaced with the maximum value of damage and the cut off criterion is $20 \%$ of maximal damage. The widths of the numerical FPZ are $75 \mathrm{~mm}$ for the reference material, $120 \mathrm{~mm}$ for material density 1.8 , and $139 \mathrm{~mm}$ for the lowest material density. They are 40 percent greater than the experimental ones. There are several reasons for this discrepancy: first the measurement from the computations ought to overestimate the FPZ width. With mesh refinements, the width of the FPZ decreases as the interpolation of displacement provides a better approximation of the solution (and sharp displacement gradients can be better captured). The second reason is due to the accuracy of the AE localization technique (about $5 \mathrm{~mm}$ for material density 2.3 and $15 \mathrm{~mm}$ for the lowest material 


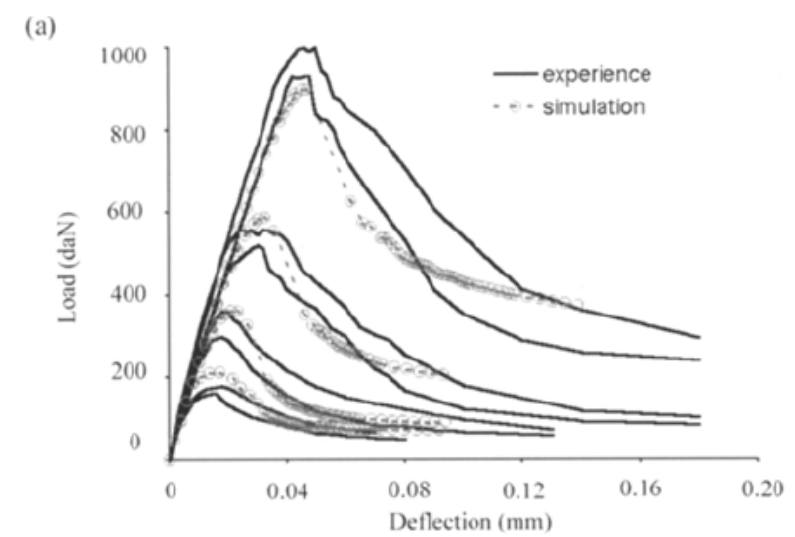

(b)

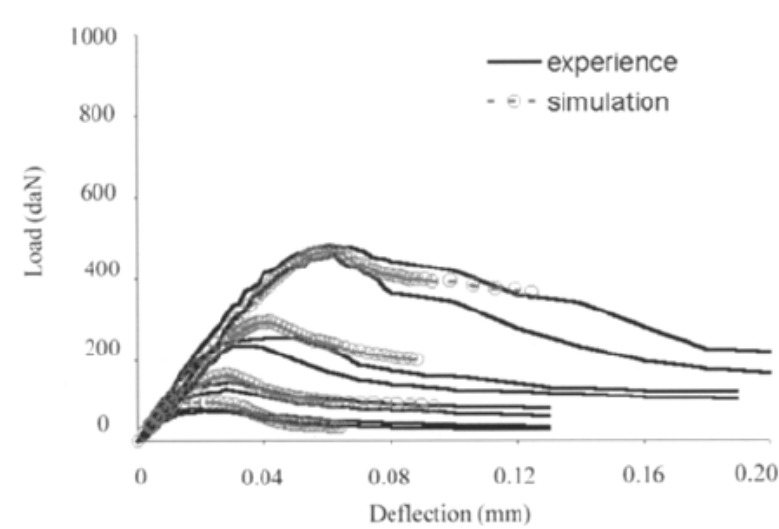

Fig. 11 - Model calibration for mortar beams with material density 2.3 (a) and 1.4 (b).

\begin{tabular}{|c|c|c|c|c|}
\hline \multicolumn{5}{|c|}{ Table 4 - Set of model parameters resulting from } \\
optimised fits \\
\hline Density & lc (mm) & $\kappa_{0}$ & At & Bt \\
\hline 2.3 & 34.4 & $4.6110^{-5}$ & 0.79 & 9836 \\
\hline 1.8 & 51.5 & $4.6610^{-5}$ & 0.65 & 9220 \\
\hline 1.4 & 64.2 & $4.7910^{-5}$ & 0.52 & 7893 \\
\hline
\end{tabular}

density). The third reason is that the experimental method cannot detect all the acoustic events. If they are located far away from the sensor locations, they can hardly be detected with a sufficient accuracy by the localization program and may be shielded by others, closer to the sensors. Finally, AE detects events that are due to micro-crack opening, but also some events due to the friction between lips of micro-cracks. These events occurs inside the FPZ (when micro-cracks have developed) and may again shield others, more remote events that are really due to micro-crack opening in the material.

A more positive observation is that the ratio between the computed and measured widths of the FPZ is constant whatever the mass density of the material as shown in Fig. 13. This indicates that there is a systematic bias between the experimental and numerical methods of determination of the width of the FPZ. In the same figure, we have plotted also the evolution of Bažant's size effect parameter $d_{0}$ and of the internal length with the mass density of the specimens. Similar variations of these four parameters are observed for all the material densities considered in this study.

Qualitatively, there is a good agreement with the result (a)

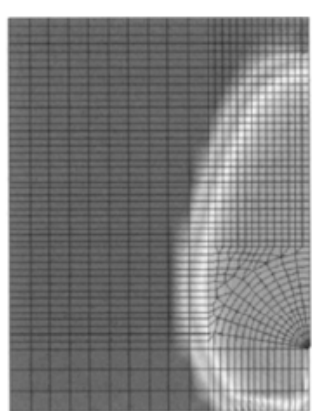

(b)

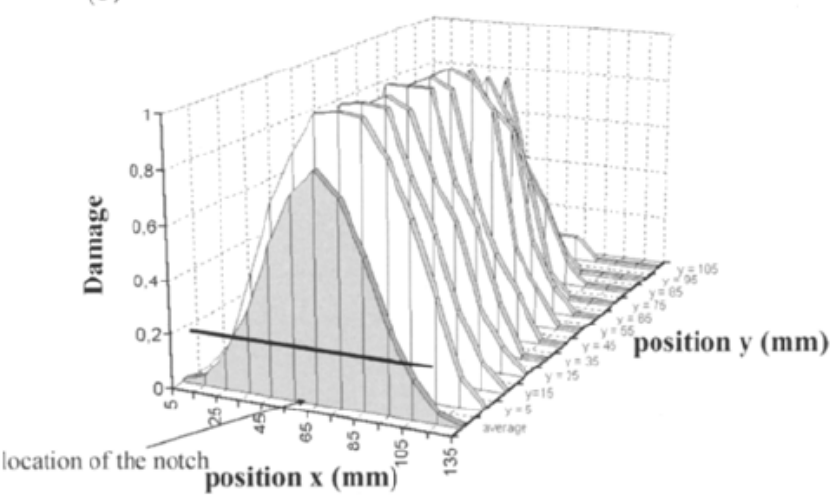

Fig. 12 - Distribution of damage for material density 2.3 (a), and damage profiles (b).

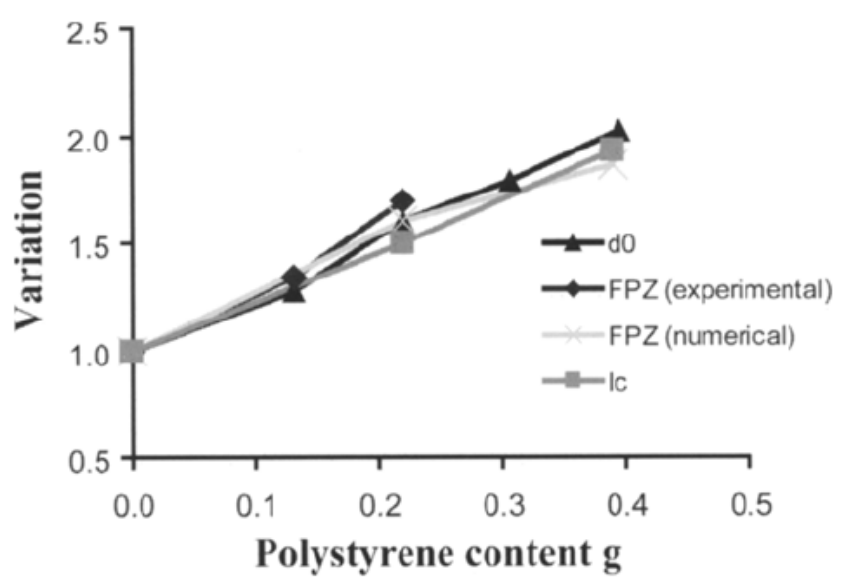

Fig. 13 - Evolution of $\mathrm{d}_{0}, \mathrm{FPZ}$ (experimental), FPZ (numerical) and internal length with polystyrene content.

obtained by Bažant and Pijaudier-Cabot [3], where the width of the zone of localized damage is proportional to the internal length of the material. Quantitatively, our results show that the coefficient of proportionality between the internal length and the width of the FPZ are different. The ratio is 1.42 if we consider the experimental value of the FPZ defined with a cut off at $20 \%$ of the maximum number of events and 2.0 if we take a cut off at $10 \%$. This ratio is 2.14 if we consider the computed value of the FPZ with a cut off at $20 \%$ of maximum damage and 2.6 for a cut off at $10 \%$. According to Bažant and Pijaudier-Cabot [3], this coefficient should be about 1.89 , but it has been obtained from a one dimensional analysis of a tensile specimen (instead of a 2D bending problem). Such results ought to be analysed in the light of expected relative errors: according 
to Le Bellégo et al. [8], the relative error in the determination of the internal length from inverse analysis of size effect tests is about $15 \%$. The relative error in the experimental determination of the width of the FPZ is at least of the order of $20 \%$ in view of the accuracy of the localization of AE events. It follows that a $35 \%$ relative error on the determination of the ratio between the internal length and the experimentally measured width of the FPZ can be expected. Considering that the $\mathrm{AE}$ technique filters, the experimental measurement ought to be a lower bound of the "true" width of the FPZ. Considering also that FE computations provide an upper bounds, our results are rather consistent.

The correlations between the internal length in the non local constitutive relations, the width of the FPZ observed with acoustic emission analysis, and the parameter $d_{0}$ of the Bažant's size effect law have been studied in this contribution. Experimental investigations have been carried out on a model mortar material with controlled macroporosity. The macro-porosity was controlled by adding polystyrene beads in a mortar matrix. Size effect experiments show that the material becomes more ductile as the initial macro-porosity increases. There is a decrease of the fracture energy and an increase of the parameter $d_{0}$. Acoustic emission tests show that the width of the FPZ increases with the porosity. The internal length obtained with the help of inverse finite element analysis increases too. The relative evolutions of these parameters with the mass density of the material are exactly the same.

From these data, it is also possible to conclude on several techniques for the experimental determination of the internal length in the non local damage model:

- The first one is the inverse finite element analysis of size effect tests, as reported by Le Bellego et al. [8].

- The second one still uses size effect tests, but only the correlation between the parameters in the size effect law and the internal length. Experiments show that the ratio of $d_{0}$ to the internal length is the same, whatever the material density. The accuracy of such a determination of the internal length relies on the capabilities of the size effect law, and of the constitutive relations to capture the observed variations of nominal stresses as closely as possible.

- Finally the third one can be based on the experimental determination of the width of the FPZ, and the ratio of this quantity to the internal length. Contrary to the first two techniques, this one does not require size effect tests but $\mathrm{AE}$ analysis devices.

Obviously, the last two methods rely on the knowledge of the ratios between the internal length, $d_{0}$, and the width of the FPZ (which in turn depend on the criteria employed for defining it from $\mathrm{AE}$ event maps). We have shown in this paper that these ratios do not depend on the amount of soft inclusions in the material (polystyrene beads). A similar result can be expected when aggregates are considered instead of soft inclusions, but the value of these ratios ought to be determined experimentally. They could be considered to be rather constant for instance for regular, of for high strength concrete, with probably different values. One should keep in mind, however, that the values of the internal lengths obtained from such ratios may be less accurate than those deriving from inverse analysis of size effect tests.

\section{ACKNOWLEDGEMENTS}

Financial support from the "Action Concertée Incitative Jeunes Chercheurs" of the French ministry of research is gratefully acknowledged.

\section{REFERENCES}

[1] Bažant, Z.P. and Planas, J., 'Fracture and size effect in concrete and other quasibrittle materials', CRC Press (1998).

[2] Hillerborg, A., Modéer, M., and Petersson, P.E., 'Analysis of crack formation and crack growth in concrete by means of fracture mechanics and finite elements', Cem. Concr. Res. 6 (1976) 773-781.

[3] Bažant, Z.P. and Pijaudier-Cabot, G., 'Measurement of the characteristic length of non local continuum', J. Engrg. Mech. ASCE 115 (1989) 755-767

[4] Mazars, J. and Pijaudier-Cabot, G., 'From damage to fracture mechanics and conversely: a combined approach' Int. J. Solids. Struct. 33 (1996) 3327-3342.

[5] Sluys L.J., 'Wave propagation, localization and dispersion in softening solids' PhD thesis, Delft University of Technology, Delft, The Netherlands (1992).

[6] Peerlings, R.H., de Borst, R., Brekelmans, W.A.M. and de Vree, J.H.P., 'Gradient enhanced damage for quasi-brittle materials', Int. J. Num. Meth. Engrg. 39 (1996) 3391-3403.

[7] Carmeliet, J., 'Optimal estimation of gradient damage parameters from localization phenomena in quasi-brittle materials', Int. J. Mech. Cohesive Frict. Mats. 4 (1999) 1-16.

[8] Le Bellégo, C., Dubé, J.F., Pijaudier-Cabot, G. and Gérard, B., 'Calibration of non local damage from size effect tests', European J. of Mech. 22 (2003) 33-46.

[9] Hild, F., Berthaud, Y. and Roux, S., 'Measurement of displacement field using a correlation method in white light' OASIS $1999-1^{\text {er }}$ Congrès européen de l'Organisation pour l'Application des Sciences de l'Ingénieur au Sport, Palaiseau, France (1999)

[10] Geers, M.G.D., de Borst, R., Brekelmans, W.A.M. and Peerlings, R.H.J., 'On the use of local strain fields for the determination of the intrinsic length scale' Journal de Physique IV 8 (1998) 167-174.

[11] Otsuka, K., 'Detection of fracture process zone in concrete by means of $\mathrm{x}$-ray with contrast medium' Fracture mechanics of concrete structures, Proc. FRAMCOS 1, Z..P. Bažant editor, Elsevier applied science (1992) 485-490.

[12] Berthaud, Y., 'Damage measurements in concrete via an ultrasonic technique. Part 1 Experiments', Cem. Concr. Res. 21 (1991) 73-82.

[13] Selleck, S.F., Landis, E.N., Peterson, M.L., Shah, S.P. and Achenbach, J.D., 'Ultrasonic investigation of concrete with distributed damage', ACI Materials Journal 95 (1998), 27-36.

[14] Maji, A.K. and Shah, S.P., 'Process zone and acoustic emission in concrete', Experimental mechanics 28 (1988) 27-33.

[15] Berthelot, J.M. and Robert, J.L., 'Modelling concrete damage by acoustic emission', Journal of Acoustic Emission 7 (1987) 43-60.

[16] Mihashi, H., Nomura, N. and Niiseki, S., 'Influence of Aggregate size on fracture process zone of concrete detected with three dimensional acoustic emission technique', Cem. Concr. Res. 21 (1991) 737-744.

[17] Otsuka, K., Date, H. and Kurita, T., 'Fracture process zone in concrete tension specimens by X-ray and $\mathrm{AE}$ techniques'. 
Fracture Mechanics of Concrete Structures; Proceedings of FRAMCOS-3 (1998) 3-16.

[18] Haidar, K., 'Damage modelling of concrete structures Numerical approaches and microstructure effects on the rupture properties', Ph.D thesis, Ecole Centrale de Nantes and Université de Nantes, France (2002) [in French].

[19] Sussman, V., 'Lightweight plastic-aggregate concrete', Journal American. Concr. Inst. 72 (1975) 321-323.

[20] Yamura, K. and Yamauchi, M., 'Use of polystyrene pieces for aggregate of concrete', Proc. Annual Conf. of ChugokuShikoku branch of JSCE (1982) 346-347 [in Japanese].

[21] Perry, S.H., Biscoff, P.H. and Yamura, K., 'Mix details behaviour of polystyrene aggregate concrete', Magazine of Concrete Research 43 (1991) 71-76.

[22] Kendall, J., Howard, A.J. and Birchall, J.D., "The relation between porosity, microstructure and strength, and the approach to advanced cement-based materials', Phil. Trans. R. Soc., London, A 310 (1983) 139-153.

[23] Zimmerman, W., 'Elastic moduli of solid containing spherical inclusions', Mechanics of Materials 12 (1991) 17-24.

[24] RILEM Draft Recommendations, 'Size effect method for determining fracture energy and process zone size of concrete', Mater. Struct. 23 (1990) 461-465.

[25] Tada, H., Paris, P.C. and Irwin, G.R., 'The stress analysis of cracks handbook', $2^{\text {nd }}$ Edition (Paris production, St. Louis, 1985).

[26] Pijaudier-Cabot, G. and Bažant, Z.P., 'Non local damage theory', J. of Engrg. Mech. ASCE 113 (1987) 1512-1533.

[27] Mazars, J., 'Application de la mécanique de l'endommagement au comportement non linéaire et à la rupture du béton de structure', Thèse de Doctorat ès Sciences, Université Paris 6, France (1984) [in French]. 